\title{
EPP, Labeling and Word Order in Arabic
}

\author{
Ameen Alahdal ${ }^{1}$ \\ ${ }^{1}$ Qassim University, Saudi Arabia \\ Correspondence: Ameen Alahdal, Qassim University, Saudi Arabia. E-mail: A.AlAhdal@qu.edu.sa
}

Received: September 18, $2020 \quad$ Accepted: February 10, $2021 \quad$ Online Published: February 21, 2021

doi:10.5539/ijel.v11n2p126 URL: https://doi.org/10.5539/ijel.v11n2p126

\begin{abstract}
This paper looks at EPP and word order in Arabic in light of Chomsky's Labeling Theory, proposed in POP and POP Extensions. In the current framework, EPP - the principle that SpecTP must be filled in - is eliminated. EPP-driven movement is reduced to labeling failure: if $T$ fails to label the structure that arises after E-merge of the subject in Spec of vP [DP vP], then filling SpecTP becomes necessary in order to 'strengthen' (the labelability of) T. Chomsky postulates two types of T: Strong and weak. English-type languages, which show poor agreement inflection, have a weak T, and therefore impose the Fill-SpecTP requirement. On the other hand, NSLs, Chomsky claims, have a strong $\mathrm{T}$ which can label the TP structure, by virtue of having rich agreement inflection. This paper shows that Chomsky's approach to EPP makes wrong predictions. Instead, a freezing effect account which also maintains a labeling system can explain the word order facts in Arabic. Crucially, the account proposed does not make resort to Chomsky's parameter of strength or otherwise of T.
\end{abstract}

Keywords: Arabic, criterial positions, labeling algorithm, EPP, word order

\section{Introduction: Labeling Algorithm}

The aim of linguistic theory since the introduction of the Minimalist Program (Chomsky 1994) has always been to reduce the theory of language to its necessary ingredients. Chomsky (2015, p. 4) remarks:

In the best case, [linguistic] phenomena would be explained by interaction of the simplest computational operation-Merge ...-interacting with general principles of minimal computation MC. The Strongest Minimalist Thesis SMT articulates this goal.

According to SMT, language is an optimal solution to legibility conditions, which come in two flavors: conditions of minimal computation (MC) and interface conditions (Note 1). Any operation that is not motivated by a condition of either sort is deemed stipulative.

In his recent work (POP, 2013; POP Extensions, 2015), Chomsky outlines yet a more 'minimalist' system of linguistic theory. Here Chomsky tries to do away with endocentricity-perhaps the only construct that has remained unquestioned ever since the introduction of the X-bar theory. Chomsky points out a conflict in syntactic theory. On the one hand, labels are necessitated by the SEM interface for the sake of full interpretation: the SEM interface should know that the new syntactic object formed is, say, a verbal element or a nominal. Under minimalist scrutiny, labels in the X-bar theory, however, turn out to be theory internal constructs, not motivated by either MC or SEM conditions, and therefore must be eliminated. A way out, Chomsky proposes the labeling algorithm in (1).

(1) Labeling Algorithm (LA)

A constructed syntactic object takes the 'label' of the nearest head by minimal search.

Thus in (2) the closest head that can serve as the label for the newly constructed object is X, the head of XP (Y, the head of YP, being "far away").

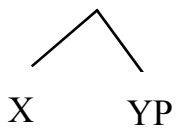

This seems straightforward. Other possibilities of Merge, known as symmetric structures, however, pose a problem for LA. Consider the derivations in (3). 
(3) a. XP YP $\quad$ b. $X \quad$ Y

In (3a), two phrases are merged; and in (3b) two heads are merged. Now these structures cannot be labeled because there is no 'nearest head': in (3a) both X and Y, heads of XP and YP, respectively, are equally near, and therefore they are both potential labels. Similarly, in (3b), both $\mathrm{X}$ and $\mathrm{Y}$ are heads and, in turn, can potentially function as labels. In POP and POP Extensions, Chomsky proposes that this labeling failure can be resolved by (i) either movement of one of the two constituents, or (ii) sharing of some feature(s) between the two heads. Under the first scenario, suppose that in (2a) XP moves. Now only one head remains accessible for LA, namely Y, and the structure is successfully labeled. The same procedure applies if YP moves. On the second scenario, suppose that $X$ and $\mathrm{Y}$ agree in some feature, say $\varphi$, then this shared feature will project, and the new syntactic object will be successfully labeled as $\langle\varphi, \varphi\rangle$.

A point is in order here before we proceed. LA crucially applies at the phase level, not at the moment of (E- or I-)merge.

Interestingly, the labeling system has been entertained to explain different phenomena (Note 2). In this paper, we consider one interesting, yet challenging consequence of LA, namely, analyzing EPP in terms of LA. Section 2 is a brief sketch of EPP. Section 3 reviews labeling approaches to EPP. Specifically, it reviews Chomsky's (POP \& POP Extensions) analysis of EPP-related phenomena in terms of labeling. Some other labeling-based approaches to EPP, Goto (2017) and Gallego (2017), are also discussed. Section 4 presents a labeling-based alternative to EPP-driven movement in Standard Arabic, without appeal to EPP. It begins with a review of the different subject positions that subjects might occupy along the clausal spine. The section also shows how the present analysis can account for the derivation of the different word orders in Standard Arabic and modern dialects of Arabic. Section 5 is the conclusion.

\section{EPP}

Let us consider the sentences in (4).

(4) a. *left

(intended 'he left')

b. John/He left

c. * seems to be a man in the room.

d. There seems to be a man in the room.

(4a) is ungrammatical in English, because it requires an explicit subject, as the grammaticality of (4b) proves. (4c) is more interesting in this context. Note that the predicate seem does not require a thematic subject; nonetheless, there must exist an overt subject for the sentence to be grammatical. That the subject position can be filled by an expletive there, which has no semantic content, indicates that the (EPP) condition is entirely structural. In fact, it is the grammaticality judgment of sentences like those in (4) that led to formulating EPP.

Null subject languages have always raised a problem for the universality of EPP, as they allow clauses without an overt subject. For instance, (5) is perfect in Arabic (Note 3).

(5) a. raH-at

went-3sf

'She went'.

$\begin{array}{llllll}\text { b. yabdu } & \text { anna } & \text { hunaaka } & \text { rajaulun } & \text { fi } & \text { alghurfah } \\ \text { seems.3sm } & \text { that } & \text { there } & \text { man } & \text { in } & \text { the.room }\end{array}$

'There seems to be a man in the room'

And to maintain the universality of principles in linguistic theory (being part of FL (Note 4)), EPP has been postulated for NSLs as well. Given the universality of EPP, linguists have disagreed on how EPP is satisfied in null subject contexts. Three approaches are available in the literature. Some linguists claim that in the derivation of SVO structures in NSLs, EPP is satisfied by movement of the preverbal subject to SpecTP, see e.g., Fassi Fehri (1993), Benmomoun (2000), Soltan (2007), Aoun et al. (2010), Saeed (2011), among others, on Arabic. Now in constructure like (5a) above, htat is, where there is no overt movement of the subject to a preverbal position, analyses seem to go along two lines: on one approach EPP is satisfied by a null expletive pro (Fassi Fehri, 1993; Cardinaletti, 1997, 2004; Mohammed, 2000; Holmberg, 2005; Sheehan, 2006, among others). In 
another approach, the EPP in such constructions is satisfied by the movement of a rich-agreement-inflected verb to T (traditional Arabic grammar; Alexiadou \& Anagnostopoulou, 1998), among others. For instance, to derive the SVO word order in Arabic, it can be argued that the subject moves to SpecTP to satisfy EPP (assuming that Agree might take place at a distance). Further, the existence of expletives like hunak in Standard Arabic (and its various forms in modern dialects) well motivates postulating an EPP on T (Note 5).

The picture is not this clean, however. In linguistic theory, and ever since it was introduced in Chomsky (1981), EPP has always been a mysterious universal (Note 6) 'principle'. As initially formulated, EPP states that a clause must have a subject; formally, SpecTP must be filled. Apart from this. it has always been felt that it is a stipulative dubious construct (e.g., Fassi Fehri, 2012; Epstein \& Seely, 1999; Boskovic, 2002; Lasnik, 2003), among many others).

There are two aspects of the EPP that have been questioned. First, it has a dubious nature; that is, it has not received a clear formal formulation. For instance, Fassi Fehri (1993, p. 54) notes that "[EPP's] exact interpretation and formulation remain open questions". Interestingly, this unclear and ever-changing nature of EPP has made Gallego (2010, p. 62) talk about different 'types' of EPP. Further, Boskovic (2002), among others, shows that EPP-related phenomena can be derived by other well-stated (and well-motivated) principles. The other aspect of EPP that has received critique is that if there is a principle like EPP, it might not be universal (e.g., Fassi Fehri, 2012; Haider, 2010, among others).

\section{EPP and Labeling Theory}

Within the labeling framework there have been attempts to eliminate EPP. EPP-driven movement is explained in terms of (failure of) labeling. Of the labeling-based accounts we will consider here Chomsky's POP \& POP Extensions, Gallego (2017), and Goto (2017).

\section{$3.1 \mathrm{EPP}$ in $\mathrm{POP}$ and POP Extensions}

In POP \& POP Extensions, Chomsky does away with EPP (as well as ECP (Note 7)) as a universal principle. EPP-driven movement is reduced to labeling failure. To get a full picture, EPP-driven movement occurs when the derivation reaches the structure in (6) (after the application of External Merge of the external argument in Spec,vP), which cannot be labeled.

\section{(6) $\left[\right.$ T $\left[\beta\right.$ (EA) $\left[\mathrm{v}^{*}[\mathrm{~V}\right.$ IA $\left.\left.]\right]\right]$}

Now, to label the structure in (6), either of the XPs moves or the two XPs should agree in some feature. As this is the thematic position of the subject (and not a checking configuration), the latter option is not felicitous. So, one phrase has to move. It happens that the subject moves (Note 8). When the subject moves, the remaining XP is successfully labeled as $<\mathrm{v}>-$ the closest head (Note 9).

In POP Extensions, Chomsky goes one step further and does away with (the universality of) EPP altogether. He claims that postulating a universal version of EPP might be "a historical accident" (p. 9). Following Rizzi's generalization of the correlation between pro drop and rich agreement, Chomsky postulates two types of T: strong $\mathrm{T}$ and weak T. A strong T, which correlates with rich verbal agreement, is one that can label; a weak T, which occurs with impoverished subject-verb agreement morphology, is one that cannot. Accordingly, NSLs, have a strong T, manifested in rich subject-verb agreement, which can label the structure in (6) as $\langle\varphi, \varphi\rangle$. Thus, SpecTP need not be filled, and, in turn, movement of the external subject to SpecTP is deemed unnecessary, because $\mathrm{T}$ is strong enough to do the job on its own. Non-null subject languages like English, on the other hand, have a weak $\mathrm{T}$ (manifested in poor subject-verb agreement) which cannot label the structure in (6). By this logic, then, movement of the external subject to SpecTP is driven by T's inability to label the structure. Having an XP in its Spec by movement of the external subject (or, alternatively, merging an expletive) makes $\mathrm{T}$ strong enough to label the structure and avoid a crash at SEM.

Theoretically, LA, as stated in (1) above has the advantage of adhering to the minimalist guidelines, especially SMT: LA is a principle of minimal computation. Further, LA, as shown in POP and POP Extensions has many interesting conceptual consequences, the most important of which is that it reduces Internal Merge to labeling failure - an interpretive principle of the SEM interface.

The main argument is that $\mathrm{T}$ in NSLs is by assumption strong, as Arabic is an NSL. The empirical consequences/predictions are:

1) Agreement holds when the subject does not move to SpecTP.

2) Constructions with the subject in Spec,TP may not realize agreement.

Let's first consider agreement and its interaction with subjects. Consider (7) below, where the subject can be 
null.

$\begin{array}{ccc}\text { (7) a. akal. a } & \text { Ahmed-u altuffaHat-a } \\ \text { ate.3sm } & \text { Ahmed-Nom the.apple-Acc } \\ \text { 'The girls ate the apple.' } & \\ \text { b. akal.a } & \text { altuffaHata } \\ \text { ate.3sm } & \text { the.apple }\end{array}$

Apparently, Chomsky's approach can explain the facts in (6). Assuming that the subject DP Ahmed does not move to SpecTP, T, or more precisely the complex [v-T] can label the structure, as $\mathrm{T}$ is strong enough (i.e., fully specified for $\varphi$ ).

Consider, however, the well-known phenomenon of agreement asymmetry in Arabic: SVO corresponds with full agreement, and VSO with poor agreement.
(8) a. albanatu
akalna
altuffaHa
the.girls.Nom ate.3pf
the apples.Acc
'the girls ate the apples.
$\begin{array}{ccc}\text { b. akalat } & \text { albanatu } & \text { altuffaHa } \\ \text { ate.3sf } & \text { the girls.Nom } & \text { the.apples.Acc }\end{array}$

This asymmetry raises a serious problem for Chomsky's framework. According to POP Extensions, $\mathrm{T}$ in Arabic is, by definition, strong (as in other NSLs), and, consequently, agreement will be observed when the subject stays in situ. Interestingly, the asymmetry in (8) yields just the opposite picture: (full) agreement holds only when the subject moves to a preverbal position. In Chomsky's labeling sense, $\mathrm{T}$ in Arabic is strong when accompanied by movement of the subject to a preverbal position (Note 10); similarly, $\mathrm{T}$ is weak when the subject stays in situ.

In fact, Soltan (2007) proposes an analysis for the agreement asymmetry in Standard Arabic in terms of strength (or otherwise) of T (Note 11). According to Soltan, $\mathrm{T}$ is strong/rich, i.e., fully inflected for phi-features, in the SVO word order (where full agreement manifests); whereas in VSO, T is poor/weak (with poor agreement on the surface). This description actually captures the facts in (8). Now, in terms of strength/weakness dichotomy, what is strong for Chomsky is weak for Soltan and vice versa.

Thus, we cannot explain the agreement-subject position facts in Arabic following POP/ POP Extensions model.

\subsection{Other Labeling-Based Approaches}

\subsubsection{Gallego (2017)}

Gallego (2017) proposes an interesting labeling-based approach to analyze EPP, without making recourse to Chomsky's feature strength. He argues that SpecTP must be filled in languages like English not because T is poor, but because $\mathrm{T}$ is actually a copy of $\mathrm{C}$. Gallego follows POP idea that copies cannot label. According to Gallego, the distinction between NSLs and non-NSLs with respect to EPP boils down to a bundling parameter: whether $\mathrm{C}$ and $\mathrm{T}$ are bundled (Note 12) together or independently. In Non-NSLs, $\mathrm{C}$ and $\mathrm{T}$ are bundled together in the lexicon, i.e., there is only one head: $\mathrm{T}$ is just a copy of C. in NSLs, on the other hand, $\mathrm{C}$ and $\mathrm{T}$ are two independent heads in the lexicon (Note 13). Though intriguing, Gallego's account unfortunately predicts that subjects consistently move to SpecTP in NSLs for the sake of labeling the structure in (6), which is not borne out in Arabic.

\subsubsection{Goto (2017)}

Goto (2017) points out that Chomsky's labeling approach to the EPP parameter (especially in POP Extensions) is stipulative a lot of stipulations. First, appealing to strong/weak parameter of $\mathrm{T}$ violates well-established minimalist guidelines. Goto refers to Chomsky's (1998) statement that "strange properties" such as strength should be eliminated from linguistic theory of FL. Another question raised by Goto relates to the asymmetry that arises in Chomsky's model between $\mathrm{T}$ and $\mathrm{R}$, both non-phase heads. Goto wonders why only $\mathrm{T}$ has the strong/weak parameter when phases should have the same properties, suggesting that dispensing with it is a minimalist gain (Note 14).

Though maintaining a labeling approach to the analysis of EPP, Goto (2017) rejects the strong/weak parameter on T proposed in POP Extensions. Instead, he adopts Fukui and Takano (1998) and Toyoshima's (2001) Head-to-SPEC movement hypothesis (Note 15). According to this hypothesis, every movement-be it of a 
phrase or a head - targets a spec position (Note 16). Further, following Alexiadou and Anagnastopoulou (1998), Goto assumes that EPP in NSLs can be satisfied by head movement of $\mathrm{v}$ to $\mathrm{T}$, although the movement here targets SpecT. According to, Goto, the parameter that sets non-null languages like English, where SpecTP must be filled by (E-/I-)merging a DP in Spec apart from null-subject languages as Arabic, where SpecT might not be overtly filled, is overtness of agreement morphology on the verb. This is how the scenario goes on. In non-null subject languages like English, V moves to SpecTP (Note 17), but because the verb is not overtly morphologically inflected for phi-features, it cannot label the SpecTP construction (phi, phi). In null subject languages, on the other hand, the verb is fully inflected, and therefore movement of the verb to T serves to label the SpecTP structure.

The main problem for Goto's analysis is that it implicitly assumes a lexicalist approach. This is evident from his speaking of the verb with full phi-features. The standard view is that Morphophonological realization of features does not take place in syntax. In fact, frameworks such as Distributed morphology and nanosyntax argue that even words are formed derivationally.

\section{The Alternative}

To account for the derivation of the different word orders in Arabic, I would like to propose a labeling approach, coupled with feature inheritance and criterial freezing. Crucially, the analysis does away with the strong/week dichotomy of T proposed in POP Extensions. We will, however, maintain Chomsky's suggestion that EPP is not universal, as also suggested in Fassi Fehri (2012). Here I would like to propose a labeling-based approach to the derivation of subjects in Arabic. The analysis makes recourse to criterial freezing and feature inheritance.

\subsection{Subject Positions, EPP and Labeling}

Subjects can be found in different positions in the clausal skeleton. Under mainstream analysis, subjects are E-merged in Spec,vP. This is presumably the thematic position reserved for subjects, necessitated by s-selectional properties of predicate. In addition to the thematic position, Belleti (2004) argues for a position at the left periphery of (the phase) vP, (below the TP inflectional layer, on a par with the left periphery of CP) that can host subjects (Note 18). In fact, Belleti shows that this position hosts the postverbal subjects in NSLs like Italian. A third position for subjects is the well-known Spec,TP, reserved normally for subjects in English-type languages. Subjects may also target a position above Spec,TP (Note 19) (and below CP), known as Spec,SubjP (Cardinelleti, 2004; Rizzi, 2004, 2006). Similarly, discussing the syntax of copular constructions, Shlonsky and Rizzi (2018) argue for two subject positions in the higher inflectional domain (apart from another (criterial) subject position outside of PredP).

Aoun et al. (2010) review the different analyses that have been proposed to account for the distribution of subjects in Standard Arabic and modern Arabic dialects. As these linguists show, in the SVO word order, there are two positions that may host the subject: SpecTP or SpecTopP, depending on whether the preverbal DP is analyzed as a subject or a topic (Note 20). In the VSO word order, the subject may be in SpecVP, the thematic position (Note 21). However, based on facts from Moroccan Arabic related to the syntax of copular constructions, Aoun et al. propose that the subject may be in SpecTP, even in the VSO word order. Hence, the positions that Aoun et al. refer to as hosts for the subject are: Spec,VP, Spec,TP and SpecTopP.

\subsection{Derivation of $S V O$}

Let's recall the initial structure we get when a subject is (E-)merged, reproduced in (9).

(9) [T [ ${ }_{\beta}$ (albanatu) [v*akalna [V albalaH]]]

Note that this structure cannot be labeled. A way to salvage the (labelibility of the) structure, suppose that the subject DP moves. As a consequence, the order that arises is SVO, and, importantly, the symmetric structure $\beta$ is successfully labeled. The question that is generally raised here is what triggers movement of the subject. Some linguists (e.g., Fassi Fehri, 1993; Aoun, 2010; Saeed, 2011) claim that movement of the subject is triggered by an EPP on T. Others, e.g., Soltan (2007), claim that the preverbal DP in the SVO order is directly merged in an A-bar position (Note 22).

Here I would follow Chomsky's labeling framework which dispenses with the EPP as a principle of FL (Note 23). In fact, Fassi Fehri (2012) questions the universality of EPP; he argues that EPP, if it exists, does not apply in Arabic. Fassi Fehri demonstrates that there is no Nominative subject in the preverbal position in Arabic, on a par with the one found in non-null subject languages such as English. For instance, an overt expletive cannot appear in raising and modal constructions (ideal structures for postulating expletives) (Note 24).
(10) a. badaa
anna
r-rajul-a
qaliq-un 


$\begin{array}{llcc}\text { seemed } & \text { that } & \text { the-man-ace } & \text { nervous-nom } \\ \text { b. y-anbagii } & \text { an } & \text { t-aquul-a } & \text { a1-haqq-a } \\ \text { should } & \text { that } & \text { you-tell-subj } & \text { the-truth-acc }\end{array}$

Literally: it should that you tell the truth

Given that EPP does not exist as a universal principle, the question of the trigger of the movement of the subject remains open. I would like to follow a proposal put forward in Alahdal (2018). Following a well-established fact to the effect that preverbal subjects in NSLs show, in addition to their A-properties, A-bar properties (e.g., Ordonez \& Trevino, 1999; Rizzi, 2006; Soltan, 2007), Alahdal argues that SpecTP becomes an A-bar position when T inherits EF (a criterial feature in Rizzi's sense, say TOP, which gets satisfied by movement of a discourserelated element to SpecTP) from C (Note 25). Notice that SpecTP turns out to be a criterial position in this case.

After the subject is E-merged, $\mathrm{T}$ is merged (along with C). Now $\mathrm{T}$ inherits its features from C. Suppose that $\mathrm{T}$ also inherits a criterial feature TOP from C and in turn SpecTP becomes an A-bar position. Now, the structure in (6) cannot be labeled. Suppose that the subject DP moves to SpecTP, triggered, not by EPP, but by TOP on T. Interestingly, an indirect consequence of this movement is that the structure downstairs is successfully labeled as both XPs - the subject DP and TP (more accurately, T) share a prominent feature TOP.

\subsection{Derivation of VSO}

In the previous section we saw how labeling can help derive the SVO word order in Arabic. We saw that one of the options that lead to labelability of the structure in (6) is when the subject DP moves, a scenario Chomsky takes to deduce EPP-driven movement from a labeling requirement. Another possibility is that some element other than the subject moves. Suppose that $\mathrm{v}$ moves to T, leaving behind [v[T [ ${ }_{\beta}(\mathrm{EA})$ [ $\left.\left.\mathrm{v}^{*}[\mathrm{~V} \mathrm{IA}]\right]\right]$.

There are two scenarios to derive the VSO word order in Arabic. Under one scenario, the subject DP remains inside the lexical projection, i.e., in SpecvP, while the verb moves to T (e.g., Koopman \& Sportiche, 1991; Mohammed, 2000; Benmamoun, 1992; Fassi Fehri, 1993). In the labeling framework, however, movement of the verb head does not seem to salvage the structure, as LA will find D as the closest head and then the structure will be labeled DP, an unwanted result. Another problem that arises here is that V-to-T movement takes place only in the past tense constructions, an idea proposed in Benmamoun (2000).

However, based on copular sentences and existential constructions, Aoun et al. (2010) argue that even in VSO constructions in Moroccan Arabic, the subject seems to be outside the lexical projection, dubbed FP. In fact, the idea that the vP has a left periphery on a par with the CP phase has been proposed by Jayaseelan (2001), Belleti (2004). Belleti shows that the postverbal subject in Italian, a NSL which allows both SVO and VSO word orders like Arabic, occupies a Focus position in the left periphery of $v$ P. I would like to argue here that this is the case in Arabic as well.

In standard Arabic, Soltan (2007, p. 41) reports the following example.
(11) jaa-uu
hum
laa
abaa-u-hum
came-3pm
they.3pm
not
fathers-NOM-their.3pm

'They came, not their fathers'

In Yemeni Arabic, question-answer exchanges seem to obtain the same judgment as in Italian reported in Belleti (2004).

(12) a. Teacher: esh fi:, Husam ?

What there, Husam

'What's happening, Husam?'

Husam: ahmed yishaghib

Ahmed misbehaving

'Ahmed is misbehaving'

b. Teacher: man shaghab, Husam?

who misbehaved, Husam?

Husam: shaghab Ahmedd. 


\section{misbehaved Ahmed}

'Ahmed has misbehaved'

This shows that postverbal subjects might carry new information focus. So we can safely suggest that the subject DP in VSO constructions is in SpecFocP at the left periphery of vP. Again in labeling terms, postverbal subjects are in a criterial position.

Another scenario under which the structure in (6) above can be labeled is when vP moves rather than the subject DP (Note 26). This seems to be the case in VOS constructions. The following examples are taken from Aoun et al. (2010, pp. 46-47)

$\begin{array}{llll}\text { (13) a. } & \text { kla } \quad \text { t-təffaha } & \text { Yomar } & \text { Moroccan Arabic } \\ \text { ate.3sm the-apple } & \text { Omar } & \\ & \text { Omar ate the apple.' } & & \\ \text { b. } & \text { gaabal mona } & \text { Pehmad } & \text { Palestinian Arabic } \\ & \text { met.3sm Mona } & \text { Ahmed } & \\ & \text { 'Ahmed met Mona.' } & & \\ \text { c. } & \text { beesit } \quad \text { Khalil } & \text { maya } & \text { Lebanese Arabic } \\ & \text { kissed.3sf Khalil } & \text { Maya } & \\ & \text { 'Maya kissed Khalil.' } & & \end{array}$

Constructions as those in (13) can be derived by movement of vP, while the preverbal DP might stay in situ. A piece of evidence comes from placement of low adverbs (Note 27).
(14) akal
altuffaha
kamil
Omar
ate. $3 \mathrm{sm}$
the apple
completely
Omar
'Omar completely ate the apple.

The adverb in (5), ideally thought to be adjoined to $\mathrm{vP}$, is placed above the subject, which might indicate that the subject remains in situ. If this derivation is on track, then this answers Chomsky's inquiry in POP Extensions as to why it is only the subject that moves out of $\mathrm{vP}$ and not $\mathrm{vP}$.

\section{Conclusion}

In this paper it has been shown that Labeling Algorithm (LA), as a minimalist construct, motivated by a SEM interface condition, along with criterial freezing, serves derive the different word orders in NSLs, Arabic in particular. What is interesting about the current proposal is that it does not resort to the 'non-minimalist' parameter of strong vs. weak T.

\section{References}

Alahdal, A. (2018). Dissolving the A/A-bar distinction: A feature inheritance-based account of preverbal DP in NSLs. Lingua, 208, 44-60. https://doi.org/10.1016/j.lingua.2018.03.005

Alexiadou, A., \& Anagnostopoulou, E. (1998). Parametrizing Agr: Word order, V-movement and EPP-checking. Natural Language and Linguistic Theory, 16, 491-539. https://doi.org/10.1023/A:1006090432389

Aoun, J., Benmamoun, E., \& Choueiri, L. (2010). Arabic syntax. Cambridge: Cambridge CUP.

Benmamoun, E. (1992). Inflectional and Functional Morphology: Problems of Projection, Representation and Derivation. Doctoral dissertation, USC, Los Angeles.

Benmamoun, E. (2000). The Feature Structure of Functional Categories: A Comparative Study of Arabic Dialects. Oxford University Press.

Blümel, A. (2012). Successive cyclic movement as recursive symmetry-breaking (pp. 87-97). Proceedings of the 30th West Coast Conference on Formal Linguistics. Cascadilla Proceedings Project.

Bobaljik, J. D., \& Thráinsson, H. (1998). Two heads aren't always better than one. Syntax, 1(1), 37-71. https://doi.org/10.1111/1467-9612.00003

Bošković, Ž. (2001). On the nature of the syntax-phonology interface: Cliticization and related phenomena. Brill.

Bošković, Ž. (2002). A movement and the EPP. Syntax, 5(3), 167-218. https://doi.org/10.1111/1467-9612.00051 
Bošković, Ž. (2007). On the locality and motivation of Move and Agree: An even more minimal theory. Linguistic Inquiry, 38(4), 589-644. https://doi.org/10.1162/ling.2007.38.4.589

Cardinaletti, A. (1997). Subjects and clause structure. In L. Haegeman (Ed.), The New Comparative Syntax (pp. 33-63). London: Longman.

Cardinaletti, A. (2004). Towards a cartography of subject positions. In L. Rizzi (Ed.), The Structure of CP and IP. The Cartography of Syntactic Structures (Vol. 2, pp. 115-165). Oxford: OUP.

Chomsky, N. (1981). Lectures on government and binding. Dordrecht: Foris. Chomsky. https://doi.org/10.1515/9783110884166

Chomsky, N. (2000). Minimalist inquiries: The framework (MITOPL 15). In Step by step: Essays on minimalist syntax in honor of Howard Lasnik (pp. 89-155). Chomsky 2015.

Chomsky, N. (2007). Approaching UG from below. In S. Uli \& G. Hans-Martin (Eds.), Interfaces + recursion = language? Chomsky's minimalism and the view from syntax-semantics (pp. 1-29). https://doi.org/10.1515/9783110207552-001

Chomsky, N. (2008). On phases. Current Studies in Linguistics Series, 45, 133. https://doi.org/10.7551/mitpress/9780262062787.003.0007

Chomsky, N. (2013). Problems of projection. Lingua, 130, 33-49. https://doi.org/10.1016/j.lingua.2012.12.003

Chomsky, N. (2015). Problems of projection: Extensions. In D. D. Elisa, H. Cornelia \& M. Simona (Eds.), Structures, strategies and beyond: Studies in honour of Adriana Belletti (pp. 1-16). https://doi.org/10.1075/la.223.01cho

Collins, C. (2017). Merge $(\mathrm{x}, \mathrm{y})=\{\mathrm{X}, \mathrm{Y}\}$. In Labels and roots. De Gruyter Mouton. https://doi.org/10.1515/9781501502118-003

Collins, C., \& Stabler, E. (2016). A formalization of minimalist syntax. Syntax, 19(1), 43-78. https://doi.org/10.1111/synt.12117

Epstein, S. D., Epstein, S. D., \& Seely, T. D. (2006). Derivations in minimalism (Vol. 111). Cambridge University Press. https://doi.org/10.1017/CBO9780511550607

Epstein, S. D., Kitahara, H., \& Seely, T. D. (2014). Labeling by minimal search: Implications for successive-cyclic A-movement and the conception of the postulate "phase". Linguistic Inquiry, 45(3), 463-481. https://doi.org/10.1162/LING_a_00163

Epstein, S. D., Pires, A., \& Seely, T. D. (2005). EPP in T: More controversial subjects. Syntax, 8(1), 65-80. https://doi.org/10.1111/j.1467-9612.2005.00075.x

Epstein, S. D., \& Seely, T. D. (1999). SPEC-ifying the GF "subject"; eliminating A-chains and the EPP within a derivational model. Ms. UMich and EMich.

Epstein, S. D., \& Seely, T. D. (2006). Derivations in minimalism (Vol. 111). Cambridge University Press. https://doi.org/10.1017/CBO9780511550607

Erteschik-Shir, N. (2005). Sound patterns of syntax: Object shift. Theoretical Linguistics, 31(1-2), 47-93. https://doi.org/10.1515/thli.2005.31.1-2.47

Erteschik-Shir, N., \& Rochman, L. (Eds.). (2010). The sound patterns of syntax. OUP. https://doi.org/10.1093/acprof:oso/9780199556861.001.0001

Fassi Fehri, A. (1993). Issues in the Structure of Arabic Clauses and Words. Dordrecht: Kluwer. https://doi.org/10.1007/978-94-017-1986-5

Fassi Fehri, A. F. (2012). Key features and parameters in Arabic grammar (Vol. 182). John Benjamins Publishing. https://doi.org/10.1075/la.182

Gallego, Á. J. (2017). Remark on the EPP in labeling theory: Evidence from Romance. Syntax, 20(4), 384-399. https://doi.org/10.1111/synt.12139

Goto, N. (2017). Eliminating the strong/weak parameter on T. Proceedings of GLOW in Asia XI, 2, 57-71.

Haider, H. (2010). The syntax of German. Cambridge University Press. https://doi.org/10.1017/CBO9780511845314

Harley, H. (2017). The "bundling" hypothesis and the disparate functions of little v. In R. D'Alessandro, I. Franco \& A. J. Gallego (Eds.), The verbal domain (pp. 3-28). Oxford: Oxford University Press. 
https://doi.org/10.1093/oso/9780198767886.003.0001

Holmberg, A. (2005). Is there a little pro? Evidence from Finnish. Linguistic Inquiry, 36, 533-564. https://doi.org/10.1162/002438905774464322

Jayaseelan, K. A. (2001). IP - internal topic and focus phrases. Studia Linguistica, 55(1), 39-75. https://doi.org/10.1111/1467-9582.00074

Jayaseelan, K. A. (2008). Bare phrase structure and specifier-less syntax. Biolinguistics, 2(1), 87-106.

Jayaseelan, K. A. (2010). Stacking, stranding, and pied - piping: A proposal about word order. Syntax, 13(4), 298-330. https://doi.org/10.1111/j.1467-9612.2010.00141.x

Koopman, H., \& Sportiche, D. (1991). The Position of Subjects. Lingua, 85, 211-258. https://doi.org/10.1016/0024-3841(91)90022-W

Lasnik, H. (2003). On the extended projection principle. Studies in Modern Grammar, 31(31), 1-23.

Mohammad, M. (2000). Word Order, Agreement and Pronominalization in Standard and Palestinean Arabic. Amsterdam: John Benjamins. https://doi.org/10.1075/cilt.181

Pollock, J.-Y. (1989). Verb movement, Universal Grammar, and the structure of IP. Linguistic Inquiry, 20, $365-424$.

Pylkkanen, L. (2002). Introducing arguments. Ph.D. dissertation, MIT, Cambridge, MA.

Rizzi, L. (1997). The fine structure of the left periphery. In L. Haegeman (Ed.), Elements of grammar: Handbook in generative syntax (pp. 281-337). Dordrecht, the Netherlands: Kluwer. https://doi.org/10.1007/978-94-011-5420-8_7

Rizzi, L. (2004). Locality and left periphery. In A. Belletti (Ed.), Structures and Beyond. The Cartography of Syntactic Structures (Vol. 3, pp. 223-251). Oxford: OUP.

Rizzi, L. (2006). On the form of chains: Criterial positions and ECP effects. Current Studies in Linguistics Series, $42,97$.

Sheehan, M. (2006). The EPP and null subjects in Romance. PhD dissertation: Newcastle University.

Shlonsky, U., \& Rizzi, L. (2018). Criterial freezing in small clauses and the cartography of copular constructions. In Freezing: Theoretical Approaches and Empirical Domains (pp. 29-65). https://doi.org/10.1515/9781501504266-002

Starke, M. (2004). On the inexistence of specifiers and the nature of heads. In B. Adriana (Ed.), The Cartography of Syntactic Structures (vol. 3: Structures and Beyond (Oxford Studies in Comparative Syntax), pp. 252-268). New York: Oxford University Press.

Toyoshima, T. (2001). Head-to-spec movement. In M. A. Galina \& A. Olga (Eds.), The minimalist parameter: selected papers from the Open Linguistics Forum (pp. 115-136). Ottawa, 12-23 March 1997. Amsterdam: John Benjamins. https://doi.org/10.1075/cilt.192.10toy

\section{Notes}

Note 1. Chomsky has always emphasized that interface conditions imposed on syntactic derivations are those related to CI interface, while "SM/ [(sensori-motor/Phon)] interface conditions seem to be irrelevant" (Chomsky, 2007, p. 11). Many linguists, however, have raised interesting issues related to the syntax-phonology interface, see e.g., Boskovic, 2001; Erteschik-Shir \& Rochman, 2010), among others.

Note 2. For instance, phenomena like successive cyclic A-bar movement (Blumel, 2012; Chomsky, 2013, 2015), successive cyclic A-movement (Epstein, Kitahara, \& Seely, 2014).

Note 3. Constructions like (i) below raise the long-standing question whether the preverbal DP is a subject, the movement of which will be triggered by EPP, or a left-dislocated element in an A-bar position, in which case it is assumed to be (E-)merged in its surface position and linked to a pro inside the clause. See below for a proposal; see Alahdal (2018) for a detailed discussion.

(i)

$$
\begin{array}{ll}
\text { maha } & \text { raHat } \\
\text { Maha } & \text { went.3sf }
\end{array}
$$

Note 4. In early generative grammar, Chomsky used the term UG (Universal Grammar) to refer to the biological 
endowment dedicated to language; in 2005, he uses the term FL (Faculty of Language); in POP (2013) he uses GP (Generative Procedure).

Note 5. Fassi Fehri (2012), however, convincingly argues that there are no nominative expletives.

Note 6. This is the standard mainstream view. Haider (2010), however, argues that EPP is not universal. He shows that German does not show this Fill-Spec-TP requirement. There is a dispute over the universality of EPP. There are two aspects to this debate. The first aspect is whether EPP is universal. The second aspect relates to how EPP is satisfied.

Note 7. In the labeling framework, ECP is also eliminated along with EPP: phenomena relate to both are uniformly explained in terms of labeling. Specifically, ECP-related phenomenon of subject extraction receives an explanation along the following lines. In Non-null subject languages like English, where $\mathrm{T}$ is weak, the subject DP cannot move further: it must stay to support T; in Null subject languages, on the other hand, since $\mathrm{T}$ is strong enough (to label TP), the subject DP can be extracted further.

Note 8. In POP Extensions, Chomsky raises the issue why vP does not move, stranding the subject, and leaves it open. It seems that this is the case in non-null subject languages, where word order is flexible. Another phenomenon that this scenario might explain is vP remnant movement in Dravidian (Jayaseelan, 2010). This topic seems to be worth investigating.

Note 9. Chomsky indicates that this analysis can also explain Alexiadou and Anagnostopoulou's (1998) observation that in a construction like (6), either of the phrases must move.

Note 10. Whether this position is SpecTP is controversial.

Note 11. Saeed (2011) also proposes a similar account.

Note 12. As Gallego (2017, p. 387) points out, that two categories can be assembled together is a cross-linguistic phenomenon investigated in a system advocated by e.g., Bobaljik and Thrainsson (1998), Pollock (1989), Rizzi (1997), Pylkkannen (2002), Harley (2017).

Note 13. Gallego's copy theory-based approach dispenses with Chomsky's $(2007,2008)$ feature inheritance.

Note 14. Goto also criticizes Chomsky's system for being silent as the correlation between rich object agreement and agreement deletion, an issue that is beyond the scope of this paper.

Note 15. Conceptually, movement should not be constrained.

Note 16. This system is also proposed in Starke (2004) and Jayaseelan (2008).

Note 17. Goto here follows Alexiadou and Anagnostopoulou (1998).

Note 18. These are known as midfield subject positions.

Note 19. Cardinelleti (2004) calls it SpecAgrSP, a term that was apparently common in the GB-days, standing for agreement inflectional heads. In the minimalist system, $T$ encompasses (perhaps all) agreement and tense inflectional properties. Cardinelleti, however, adopts a Rizzian cartographic view which believes in decomposing (traditional) heads to their distinctive features that correspond to distinct inflectional projections.

Note 20. See Author (2018) for a detailed overview and an analysis.

Note 21. Aoun et al. (2010, p. 51, ft. 2) allude to variants to this analysis that take the postverbal subject to be "within a predicate phrase or a functional category that dominates VP". This position seems to be SpecvP.

Note 22. See Alahdal (2018) for a detailed overview.

Note 23. EPP has always been a mysterious construct. Several linguists have tried to eliminate it. For instance, Fassi (1993) tried to deduce EPP effects from other modules such as Theta Criterion and Case theory.

Note 24. In fact, Fassi Fehri conjectures that expletives can be explained in terms of case.

Note 25. See Chomsky (2013) for the possibility of inheritance of $\varphi$ - features in addition to phi-features.

Note 26. In POP Extensions, Chomsky wonders why it is only the subject DP that moves. However, it seems that movement of the $\mathrm{vP}$ is also attested.

Note 27. This also suggests that the VOS is not derived by some VP-remnant movement, as there can be no intervening element between the verb and the object (Jayaseelan, 2010). 


\section{Copyrights}

Copyright for this article is retained by the author, with first publication rights granted to the journal.

This is an open-access article distributed under the terms and conditions of the Creative Commons Attribution license (http://creativecommons.org/licenses/by/4.0/). 